www.jmscr.igmpublication.org

Impact Factor (SJIF): 6.379

Index Copernicus Value: 79.54

ISSN (e)-2347-176x ISSN (p) 2455-0450

crossrefDOI: https://dx.doi.org/10.18535/jmscr/v6i11.88

Journal Of Medical Science And Clinical Research

IGM Publication

An Official Publication of IGM Publication

\title{
Melanotic Neuroectodermal Tumor of Infancy: A Rare Case Report
}

\author{
Authors \\ Dr Karuna Gupta ${ }^{1}$, Dr Priyanka Sharma ${ }^{2}$, Dr Deepika Hemrajani, \\ Dr Krishna Sireesha Sundaragiri ${ }^{4}$, Dr Ajay Yadav ${ }^{5}$ \\ ${ }^{1}$ Professor, Pathology, SMS Medical College, Jaipur \\ ${ }^{2}$ Senior Resident, Pathology, SMS Medical College, Jaipur \\ ${ }^{3}$ Associate Professor SMS Medical College, Jaipur \\ ${ }^{4}$ Assistant Professor at RUHS Dental College of Dental Sciences, Govt. Dental College of Jaipur \\ ${ }^{5}$ Professor and Head, Department of Pathology, SMS Medical College, Jaipur, India
}

\section{Introduction}

Melanotic Neuroectodermal Tumor Of Infancy (MNTI) is a rare, benign, pigmented neoplasm arising from neural crest. ${ }^{1,2}$ Clinical presentation is often painless, locally aggressive, rapidly expansile growth causing facial disfigurement. ${ }^{2}$ In the literature, neoplasm has been known by various synonyms like congenital melanocarcinoma, retinal analage tumor, pigmented congenital epulis and melanotic progonoma. ${ }^{1,3}$ This lesion is found mainly in children below 1 year of age. Rare cases have been reported in older children and adults also., Gender predilection is not seen through literature. ${ }^{4}$ 93\% of MNTI occurred in head and neck region with unique predilection for anterior maxilla, although cases including brain, skull, epididymis have also been reported. ${ }^{5}$ MNTI has a recurrence rate of $15 \%$ and show malignant differentiation in $6.6 \%$ cases, hence long term follow up after surgical excision is required. ${ }^{6}$ Plain radiographs show expansile areas of translucency with poor circumscription probably as result of rapid tumor growth and local aggressiveness. ${ }^{5}$ The present case report describes a case of MNTI in a 1.5 month old male child along with brief review of literature and pathological differential diagnosis.

\section{Case Report}

1.5 month old male baby presented with 15 days history of firm, painless, rapidly growing left maxillary swelling. There was history of normal pregnancy and delivery and no medication during pregnancy. On intraoral examination, blue-pink coloured firm swelling was seen measuring approximately $3 \times 3 \mathrm{~cm}$ in left side maxilla. Dilated veins were seen over the swelling. Upper lip was stretched and lifts up. Provisional diagnosis of dentigerous cyst, vascular malformation or hemangioma was made. Computed tomography scan shows homogenous translucent lesion in the maxillary bone on left side. Surgical excision was done under general anaesthesia.

Clinical differential diagnosis of jaw swelling in infant are usually benign odontogenic cysts and congenital epulis although neoplasm with rapid growth includes embryonal rhabdomyosarcoma, Ewings sarcoma, neuroblastoma, melanoma, burkits lymphoma and teratoma. 
Urinary Vanillylmandelic Acidwas normal (2.8 $\mathrm{mg} / 24$ hours).

The gross examination of the specimen revealed $3 \times 3 \mathrm{~cm}$, firm, slight blue coloured tumor with single developing tooth attached. Cut surface of the tumor was blue-black due to pigmentation.

Microscopic examination shows a biphasic population of cells arranged in nests and clusters, separated by fibrovascular stroma. The two population comprised of large melanotic (pigmented) cells and small round (nonpigmented) cell with scant cytoplasm. Large epithelial cells contain melanin pigment. The small round cells have features of primitive neuroepithelial cells. Based upon these findings tumor was dignosed as MNTI. Immunohistochemical marker study (IHC) was done for confirmation.

IHC revealed positive staining for HMB-45 in the melanin containing large epithelial cells and negative staining in small round cells. Expression of synaptophysin was predominantly in small neuroblastic cells but large epithelial cells also show focal positivity. S-100 was negative which helps to rule out melanoma. Cytokeratin was positive.

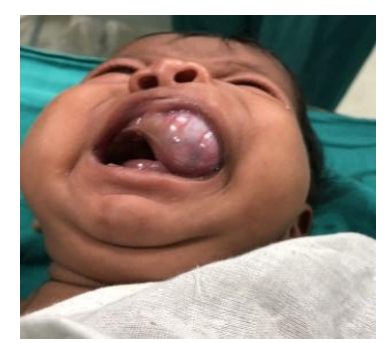

(a) Clinical photograph showing swelling in left maxillary region.

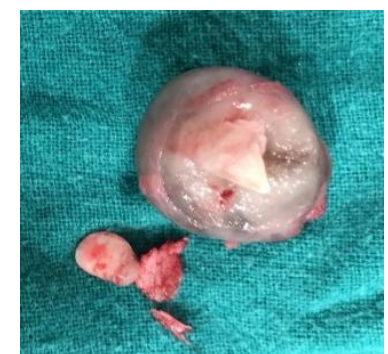

(b) Image showing excised specimen with single deciduous incisior.

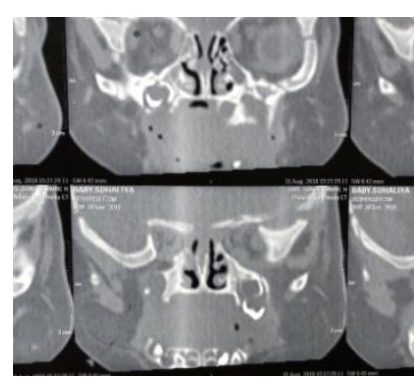

(c) Enhanced CT scan show homogenous mass in the left maxilla.

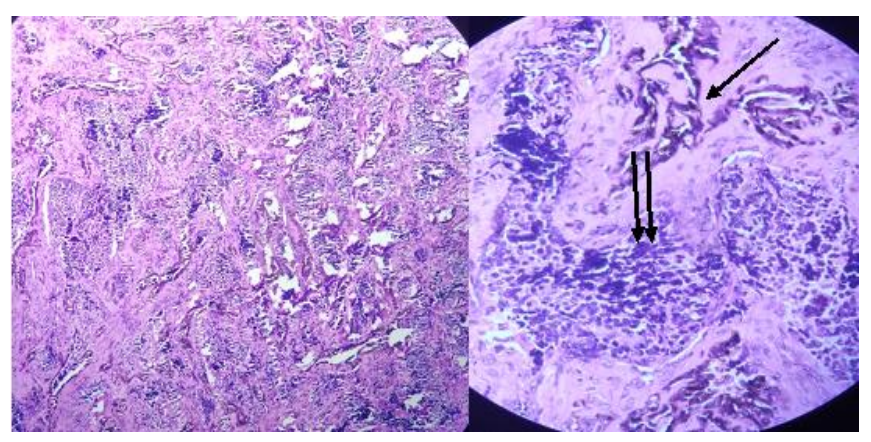

(d) \& (e) H\&E stain shows dual population of cells. Large melanin containing pigmented cells (single arrow) and small round monomorphic neuroblastic cells (double arrow).

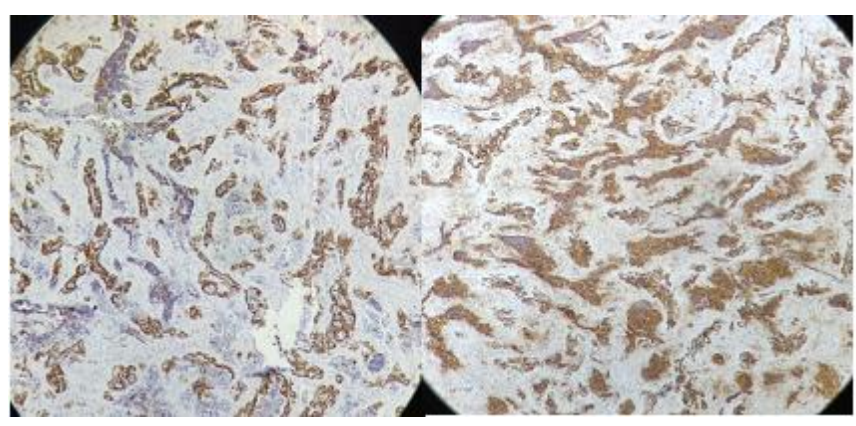

(f) HMB-45 positivity in large polygonal melanin containing cells. (g) Positive synaptophysin staining in small neuroblastic cells.

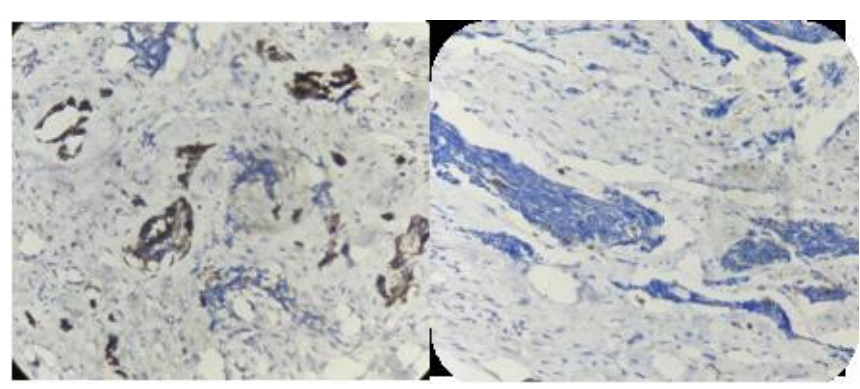

(h) \& (i) Focal cytokeratin positive staining and negative S-100 staining. 


\section{Discussion}

MNTI is a rare neoplasm affecting maxilla followed by calvaria and mandible. ${ }^{1}$ The origin of tumor is controversial. Rarely it can arise in the skull, mandible, brain, meninges, retina, mediastinum, bone, soft tissue, testies and epididymis. ${ }^{1-4}$ Krompecher in 1918 reported a case of pigmented tumor of maxilla associated with developing tooth in 2 month old baby and reported as congenital melanocarcinoma. ${ }^{2,8}$ other designations for the same neoplasm was retinal analage tumor, pigmented ameloblastoma, pigmented epulis and melanotic progonoma. ${ }^{1,9,10}$ Borello and Gorlin in 1966 first coined the term Melanotic Neuroectodermal Of Infancy based on IHC, ultrastructure, electron microscopic studies and a high urinary VMA levels. ${ }^{11}$ High urinary VMA level suggest neural crest origin of tumor. Many case reports with normal urinary VMA levels also reported in literature. ${ }^{3}$ The IHC and ultrastructural features of MNTI cells make them very similar to neural crest cell origin. Diagnosis before surgical excision and distinction from other paediatric small round cell tumor (rhabdomyosarcoma, neuroblastoma, melanoma and lymphoma) is mandatory to plan the complete surgical resection and reducing the possibilities of tumor recurrence. ${ }^{12}$ classic clinical presentation is rapidly growing, painless, expansile, non ulcerated, unencapsulated partly pigmented mass, typically in the maxillary region. It has tendency for local invasion therefore aggressive surgical approach consisting of complete surgical excision and long term follow up is recommended. Microscopically MNTIs are biphasic tumors with one cell population consisting of cuboidal epithelial cells with open vesicular nuclei arranged in tubular and alveolar pattern. These cells have abundant melanin pigment. Another cell type is small dark round cells with hyperchromatic nucleus and minimal cytoplasm, arranged in nests within the fibrovascular stroma. It has appearance of neuroblast.

IHC markers are helpful in differentiating MNTI from embryonal rhabdomyosarcoma (desmin and myoglobin positive), Melanoma (s-100 positive, while negative in MNTI), EWING sarcoma (CD99 and FLI 1 positive), lymphomas ( LCA positive).

MNTIs are reactive for HMB-45 and synaptophysin both indicate melanocytic and neuroblastic differentiation of the cells (biphasic).

\section{Conclusion}

MNTI is rare benign paediatric neoplasm with tendency for local invasion and recurrence. Exact diagnosis by histomorphology combining with IHC is recommended. Complete surgical excision and long term follow up is required.

\section{Reference}

1. David R. Mirich, Susan I Blaser, Derek C. Harwood-Nash, Derek C. Armstrong, Larry E. Becker, Jeffrey C. Posnick. Melanotic neuroectodermal tumor of infancy: Clinical, radiological and pathologic findings in five cases.AJMR : 12 July/ August 1991.

2. Balaji Babu Bangi and AvinashTejasvi M. L. Melanotic neuroectodermal tumor of infancy: A rare case report with differential diagnosis and review of literature. Contemporary Clinical Dentistry Jan-Mar 2012, Volume 3, Issue 1.

3. P. Agrawal, S. Saxena, S. Kumar and R. Gupta. Melanotic neuroectodermal tumor of infancy: Presentation of a case affecting the maxilla. Journal of oral and maxillofacial pathology, Jan-Jun 2010, Vol. 14, Issue 1.

4. P. Agrawal, V. Agrawal and V. K. Raina. Melanotic neuroectodermal tumor of infancy: Case report of an unusual tumor. Indian J. Plastic Surg, July-December 2003, Vol. 36 Issue 2.

5. S. Chaudhary, N. Manuja, C. T. Ravishankar, and A. Sinha. Oral melanotic neuroectodermal tumor of infancy. JISPPD Jan-Mar 2014, Vol. 32, Issue 1. 
6. Madrid C, Aziza J, Hlali A, Bouferrache $\mathrm{K}$, Abarca M. Melanotic neuroectodermal tumor of infancy: A case report and review of the aetiopathogenic hypotheses. Med Oral Pathol Oral Cir Bucal 2010; 15; e 739-42.

7. Maria Gaiger de Oliveria, Thompson LD, Chaves AC et al. Management of Melanotic neuroectodermal tumor of infancy. Ann Diagn Pathol 2004:8:207-12.

8. Krompecher E. Zur Histogenese and morphologic der adimantinome and sonstiger keifergeschwulste. Beitr Path anat 1918; 64: 165-97.

9. Nathanson NR, Tedeschi LLG. Melanotic progonoma- A tumor of infancy. Oral Surg Oral Med Oral Pathol 1967; 23 (3): 354361.

10. Allen MS Jr, Harrison W, Jahrsdoerfer RA. "Retinal analage" tumors. Melanotic progonoma, melanotic adamantinoma, pigmented epulis. Melanotic neuroectodermal tumor of infancy. Am J Clin Pathol 1969;(51)3 : 309-314.

11. Borello ED, Gorlin RJ. Melanotic neuroectodermal tumor of infancy: a neoplasm of neural crest origin.1966; 19: 196-206.

12. Galera-Ruiz H, Gomez-Angel D et al. FNAC in the pre-operative diagnosis of melanotic neuroectodermal tumor of infancy. J Laryngol Otol 1999; 113: 581-4. 